\title{
High resolution aeromagnetic anomaly map of Tenerife, Canary Islands
}

\author{
Alicia García ( $\left.{ }^{1}\right)$, Massimo Chiappini ( $\left.{ }^{2}\right)$, Isabel Blanco-Montenegro $\left({ }^{3}\right)$, Roberto Carluccio $\left({ }^{2}\right)$, \\ Francesca D'Ajello Caracciolo $\left({ }^{2}\right)$, Riccardo De Ritis $\left({ }^{2}\right)$, Iacopo Nicolosi $\left({ }^{2}\right)$, Alessandro Pignatelli $\left({ }^{(}\right)$, \\ Nieves Sánchez $\left({ }^{1}\right)$ and Enzo Boschi $\left(^{(}\right)$ \\ (1) Departamento de Volcanología, Museo Nacional de Ciencias Naturales, CSIC, Madrid, Spain \\ ${ }^{(2)}$ Istituto Nazionale di Geofisica e Vulcanologia, Roma, Italy \\ (3) Departamento de Física, Universidad de Burgos, Spain
}

\begin{abstract}
This study presents magnetic anomaly data from a new high-resolution, low-altitude helicopter-borne magnetic survey recently collected on and offshore Tenerife in the Canary Archipelago. The Italian Istituto Nazionale di Geofisica e Vulcanologia (INGV) in collaboration with the Museo Nacional de Ciencias Naturales of the CSIC of Spain conducted the survey in 2006. The data for Tenerife and surrounding marine areas were processed into digital total intensity magnetic anomalies for geomagnetic epoch 2006.4. Relative to previously available higher altitude magnetic survey data, the new survey mapped higher resolution anomalies with significantly improved spatial details, especially over Las Cañadas caldera and Teide-Pico Viejo complex in the central part of the island. A good correlation is evident between known geological structures and the magnetic anomalies, where the new shorter wavelength anomalies facilitate more detailed and comprehensive geological interpretations.
\end{abstract}

Key words magnetic anomalies - Tenerife - Teide volcano - aeromagnetism - potential fields

\section{Introduction}

The Canaries are a group of seven volcanic islands located in the eastern central Atlantic near the African coast. Tenerife is the largest island of the archipelago and represents the emerged portion of a huge volcanic edifice that rises about $7 \mathrm{~km}$ from the seafloor. The oldest subaerial materials of Tenerife correspond to the shield basaltic stage with an age of about $12 \mathrm{Ma}$ (Guillou et al., 2004). In the central part of the Tenerife, the Teide-Pico Viejo volcanic complex

Mailing address: Dr. Massimo Chiappini, Istituto Nazionale di Geofisica e Vulcanologia, Via di Vigna Murata 605, 00143 Roma, Italy; e-mail: massimo.chiappini@ingv.it with an age of about $180 \mathrm{ky}$ and the maximum topographic height of $3718 \mathrm{~m}$ represents the most recent phase of activity. This composite stratovolcano was constructed inside the $\mathrm{Ca}-$ nadas caldera (fig. 1) that has been variously attributed to multiple collapses and landslides (i.e. Carracedo, 1994; Watts and Masson, 1995; Ancochea et al., 1999; Martí and Gudmundsson, 2000).

Our knowledge of the geological properties and evolution of Tenerife improved significantly as the result of an international effort to study the Teide volcano from a multidisciplinary perspective. Since 1992, the European Union has investigated Tenerife as one of its six European Laboratory Volcanoes. As part of this effort, the Spanish Instituto Geográfico Nacional carried out a regional aeromagnetic survey of the $\mathrm{Ca}$ nary archipelago in 1993. Over Tenerife, the survey mapped lines at the spacing of $2500 \mathrm{~m}$ in the N-S direction at a constant altitude of $3200 \mathrm{~m}$, except over the central part of the is- 


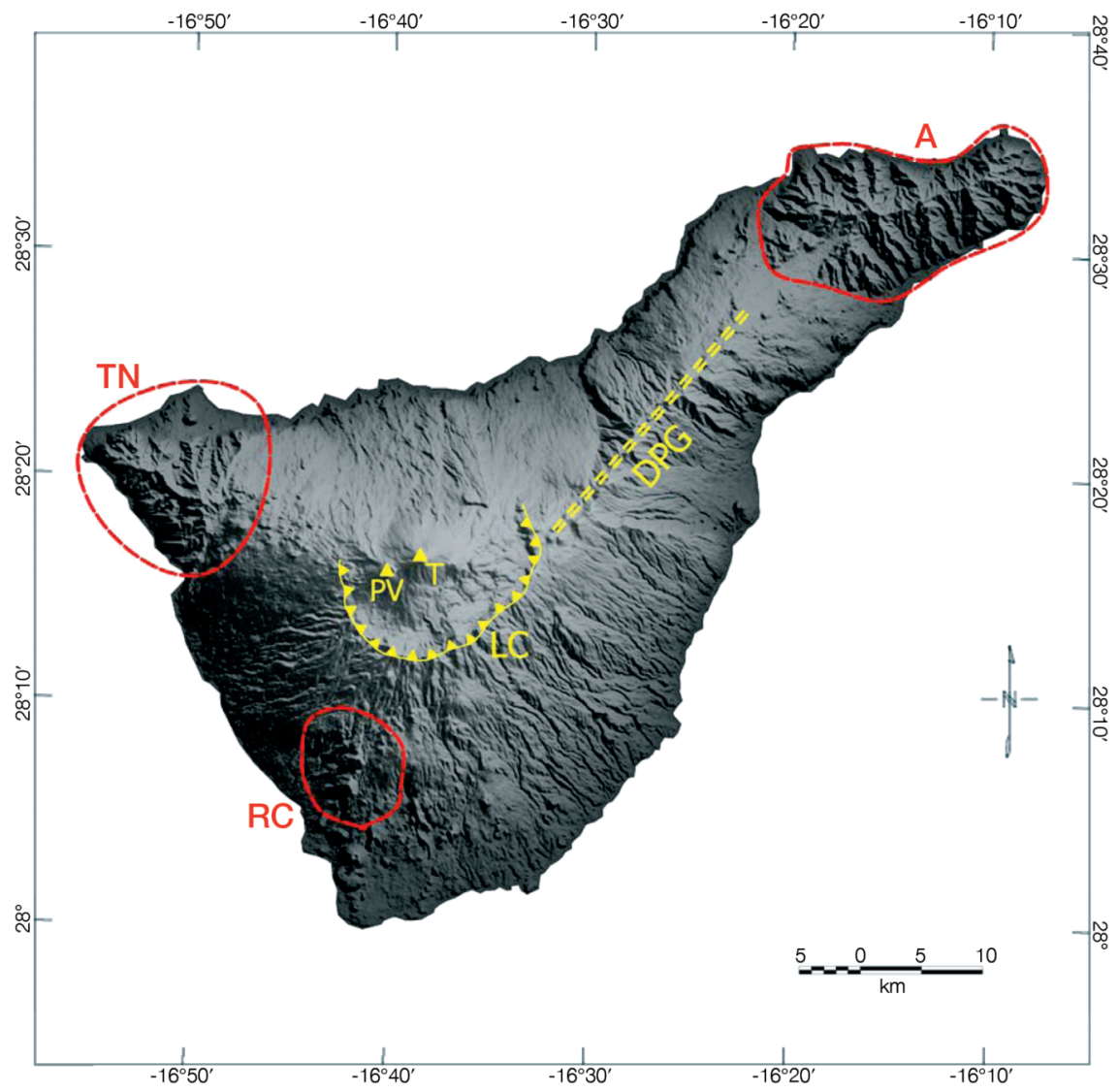

Fig. 1. Digital elevation model of Tenerife featuring the Las Cañadas caldera (LC), and the volcanic edifices of Teide (T), Pico Viejo (PV), Anaga (A), Teno (TN), Dorsal de Pedro Gil (DPG), and Roque del Conde (RC).

land where the flight height was $3800 \mathrm{~m}$ above sea level (a.s.1.) (Socías and Mézcua, 1996).

This aeromagnetic survey effectively sampled the larger scale features of the volcanic edifice and provided a magnetic image of Tenerife at the constant altitude of $3800 \mathrm{~m}$. García et al. (1997), Blanco-Montenegro (1997), and Araña et al. (2000) related the intrusive core of the island and its magmatic feeding system with positive magnetic anomalies.

Tenerife last erupted in 1909, but the significant increase in seismic events with epicentres located inland on Tenerife since spring 2004 suggests that the volcanic system may be reawakening. This anomalous seismic activity includes five felt earthquakes accompanied by increased fumarolic activity at the Teide summit and diffuse emissions of carbon dioxide along the Santiago Rift (García et al., 2006). Analysis of microgravity data suggests that magma may be recharging beneath the northwestern rift zone of Tenerife and reawakening the volcano (Gottsmann et al., 2006).

This reactivation evidence has resulted in the call for the scientific community to collect new data on the subsurface properties of Tenerife. High-resolution, low-altitude aeromagnetic surveys, in particular, have considerable utility in studies of active volcanoes (e.g., Lénat et al., 2001; De Ritis et al., 2005; Blanco-Montenegro 
et al., 2007; De Ritis et al., 2007). This surveying identifies high-frequency magnetic anomalies that map distributions of outcropping or buried intrusions, vents, faults, and other volcanic features. This approach is particularly useful for studies of active volcanic islands and their surrounding offshore areas where the geology is remote and mostly inaccessible.
Due to the 2004 reactivation, the Spanish Ministry of Education and Science funded the TEGETEIDE project, which is a multidisciplinary effort of more than 100 researchers from different institutions and countries coordinated by the $\mathrm{Na}$ tional Research Council of Spain (CSIC). As part of this initiative, the national institutions (INGV and CSIC) of Italy and Spain, respectively, col-
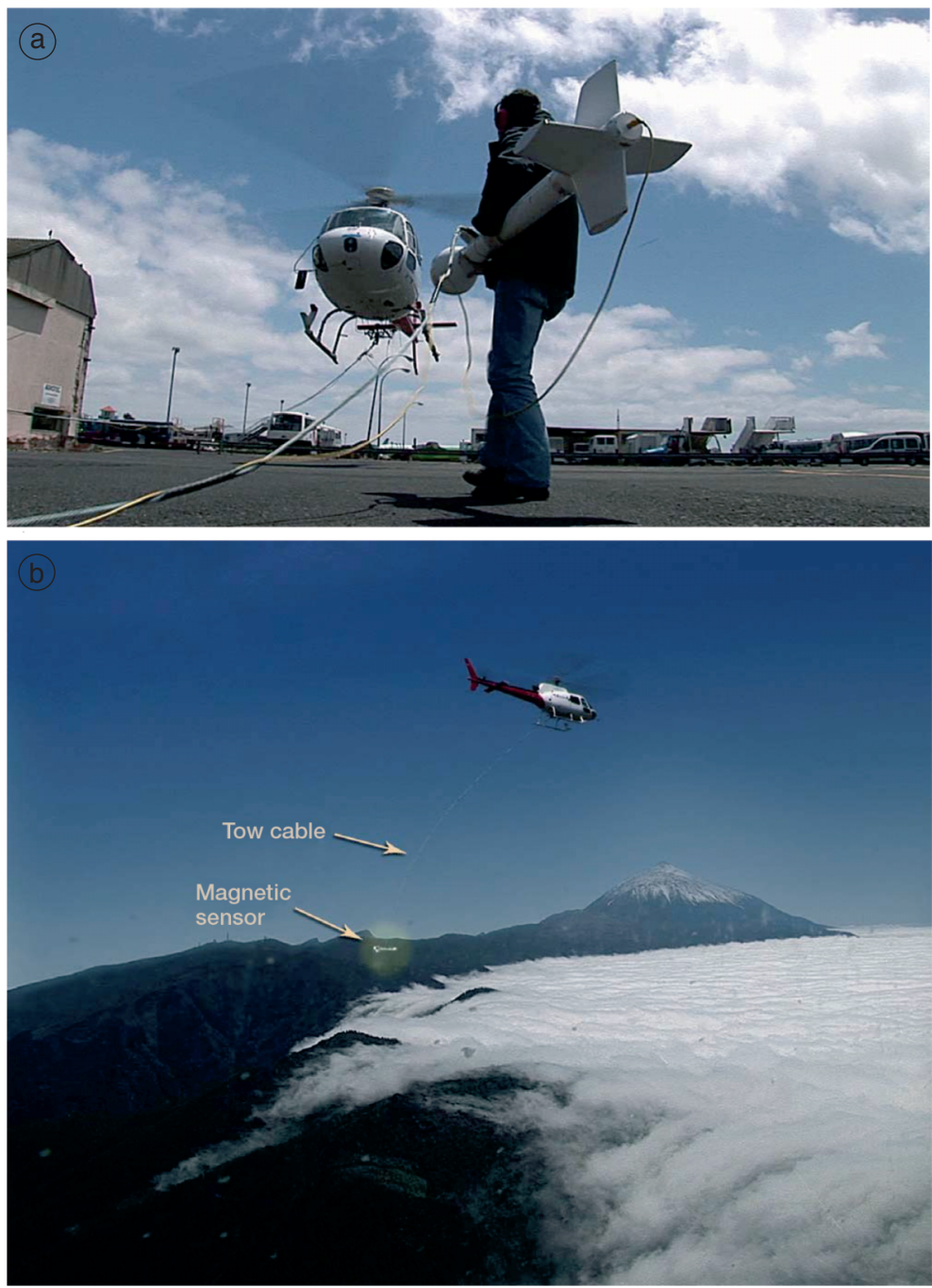

Fig. 2a,b. a) Logistical operations during takoff and landing for launching and retrieving the towed airborne magnetometer bird attached to the barycentre hook of the Aerospatiale Squirrel AS 350 helicopter; b) magnetic sensor and tow cable while airborne with the Teide volcano in the background. 


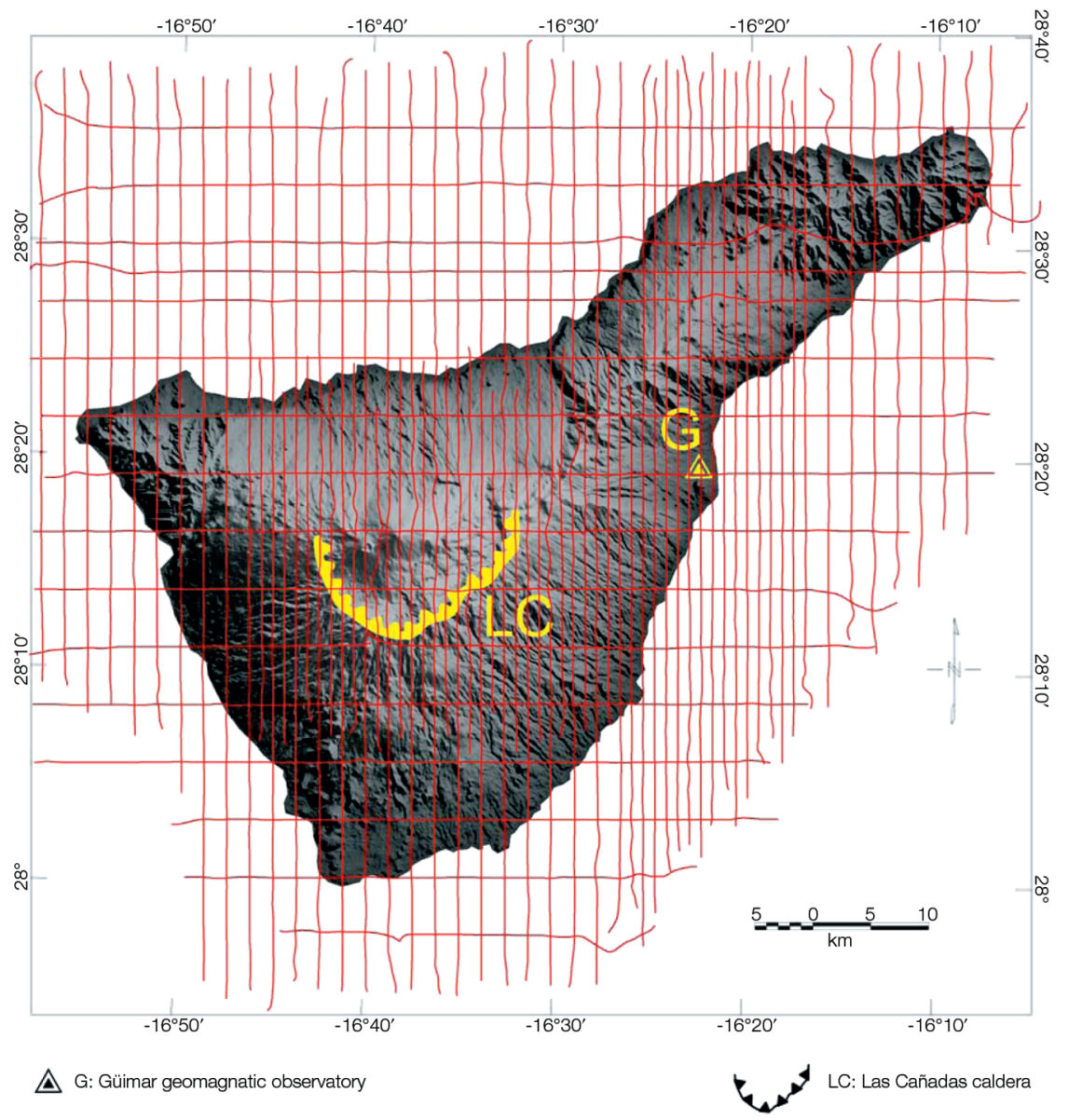

Fig. 3. Distribution of the aeromagnetic profiles and tie lines. Latitude and longitude are north and west from Greenwich, respectively. The G symbol indicates the location of Güimar geomagnetic observatory of the Instituto Geográfico Nacional of Spain.

laborated to collect new lower altitude, higher resolution magnetic data for Tenerife and its offshore areas. In the following sections, we describe the acquisition, processing, and analysis of these new state-of-the-art helicopter survey data.

\section{The magnetic survey}

Conducted in April, 2006, the magnetic survey used an Aerospatial Squirrel AS 350 helicopter operated by a local company (Helicópteros Insulares S.L.), which towed an optically pumped Cs-vapor magnetometer owned by INGV within an aerodynamical casing (fig. $2 a, b$ ). The survey covered the entire island of Tenerife with N-S profile lines, which were spaced at $1000 \mathrm{~m}$ in the central and the eastern parts of the survey area, and at $2000 \mathrm{~m}$ in the rest of the island and its surrounding marine areas. The tie lines were flown E-W at $5000 \mathrm{~m}$ intervals (fig. 3). The survey obtained 4977 line-kilometers of data in 14 flights over 9 days.

The survey strategy and operational parameters were comparable to those of other campaigns that the INGV Airborne Geophysics Science 
Team conducted over volcanic areas (e.g., Chiappini et al., 1998, 2002; De Ritis et al., 2005, 2007). An onboard satellite-based navigation system continuously acquired the helicopter's position, which was differentially corrected using a ground-based GPS station for a very accurate location. Total intensity magnetic field data were sampled at the rate of $10 \mathrm{~Hz}$. The flight altitude was maintained at the barometric altitude of 2200 $m$ above the ground, except in the area of Las Cañadas caldera where the peak of Teide reach $3718 \mathrm{~m}$ of altitude. Here, data were acquired using draped profiles flown at the laser altimetrymeasured terrain clearance of about $150 \mathrm{~m}$.

The records from the Guiímar geomagnetic observatory of the Spanish Instituto Geográfico Nacional were used to correct the survey data
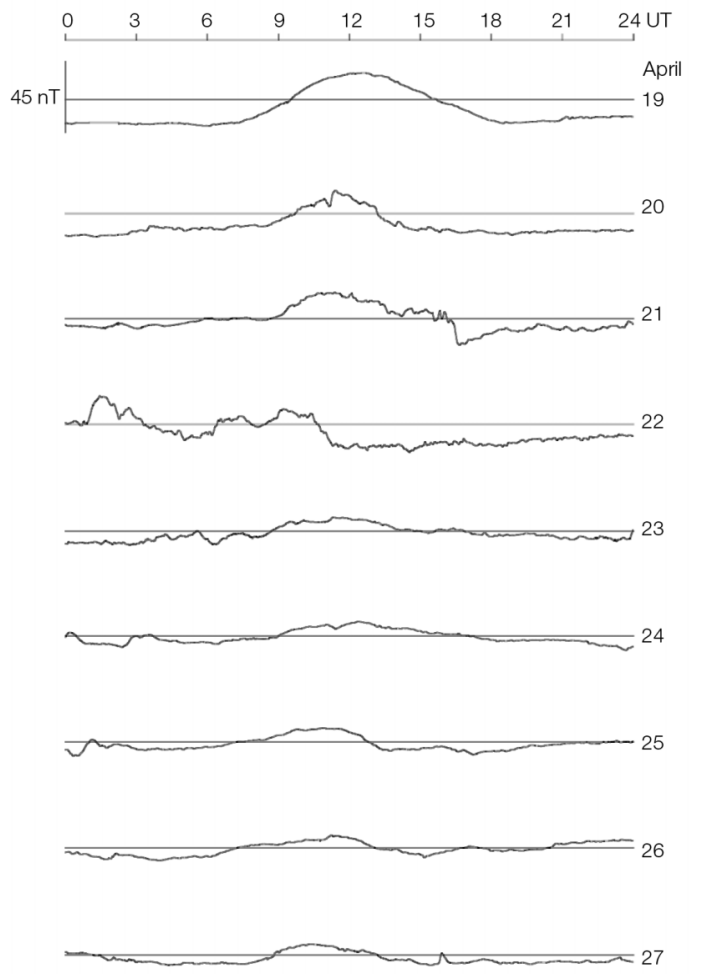

April

Fig. 4. Diurnal field variations recorded in Universal Time (UT) at the Güímar geomagnetic observatory from 19-27 April 2006. for diurnal magnetic variations. Figure 3 shows the location of the geomagnetic observatory $\left(28^{\circ} 19^{\prime} 12^{\prime \prime} \mathrm{N}\right.$; $16^{\circ} 25^{\prime} 48^{\prime \prime} \mathrm{W} ; 848 \mathrm{~m}$ elevation) along with the surveyed flight lines.

\section{The computation of the magnetic anomaly field}

With each total magnetic field observation, the survey obtained the corresponding latitude, longitude, GPS time, barometric altitude, terrain clearance, and GPS-altitude. Positioning data were recorded every second in the onboard data acquisition system and the ground-based 12 channel GPS receiver.

The magnetic field observations were corrected for the diurnal variations recorded at the Güímar geomagnetic observatory. Figure 4 gives examples of the Güímar magnetograms that were used to remove the diurnal variation from the survey data. The survey operated during geomagnetically quiet times when the planetary geomagnetic $\mathrm{K}$ index was below 3.0 except for 9:00 to 12:00 UT on April 22 when it reached 4.7.

The magnetic survey data were corrected to the 2006.4 geomagnetic epoch by

$$
E_{s}^{06}=E_{\mathrm{obs}}^{06}+\left(E_{s}^{t}-E_{\mathrm{obs}}^{t}\right)
$$

where $E_{s}^{t}=$ magnetic field value (nT) at station $s$ at time $t ; E_{\text {obs }}^{t}=$ value observed at time $t$ at the reference observatory; $E_{\text {obs }}^{06}=$ value at the observatory at $2006.4 ; E_{s}^{06}=$ value at station $s$ reduced to 2006.4

The anomaly values were obtained by subtracting the calculated main field component of the Earth's magnetic field from each diurnally corrected survey point using the 10th generation of the International Geomagnetic Reference Field (IGRF) model (MacMillan and Maus, 2005).

After the base station correction and IGRF reduction, crossover analysis minimized the remaining discrepancies in the magnetic field values at the intersections of the profiles and tie lines. These discrepancies reflected the different flight elevations between survey and tie lines, especially in the draped portion of the survey. These altitude differences also reflected 


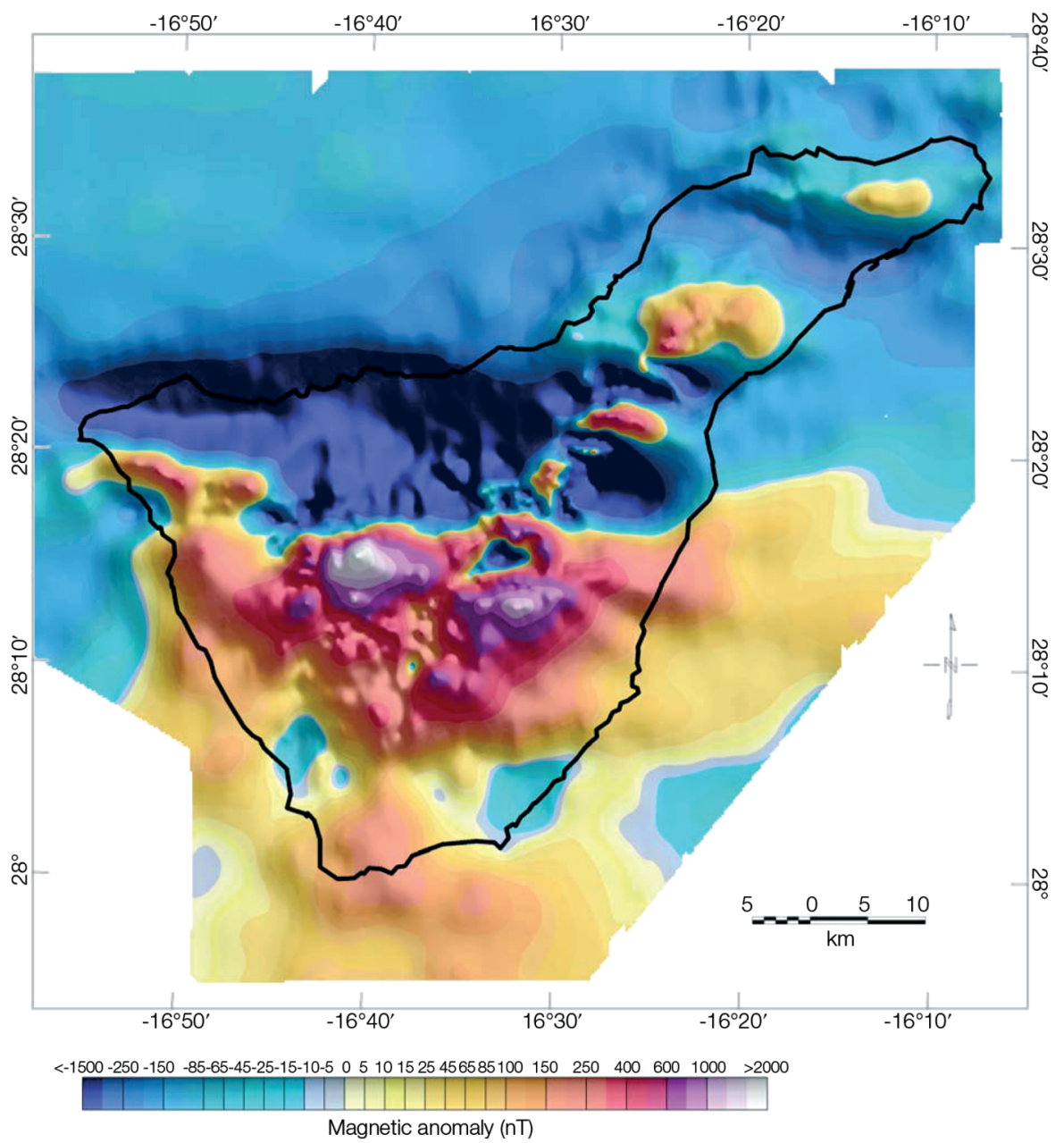

Fig. 5. Colour shaded relief magnetic anomaly map (total intensity) of Tenerife Island with colour intervals adjusted to the amplitude content of the whole grid. Latitude and longitude are north and west from Greenwich respectively.

the lower terrain clearances that the flight lines ascending the Teide volcano experienced relative to the descending flight lines. The intersection points between survey and tie lines were statistically leveled (e.g., Chiappini et al., 2000, 2002) to yield the overall root-mean-square intersection difference of less than $1 \mathrm{nT}$.

The anomalies were then gridded at the interval of $250 \mathrm{~m}$ and plotted into UTM projection using the WGS84 map datum with central meridian $15^{\circ} \mathrm{W}$ (UTM zone $28 \mathrm{~N}$ ). Figures 5 and 6 show the gridded anomalies in shaded relief and contour formats, respectively, whereas Plate 1 gives a large map of these magnetic anomalies at scale 1:100000. In fig. 5, anomalies of the total intensity of the Earth's magnetic field are displayed in colour intervals adjusted to the frequency content of the whole grid. In fig. 6 , the same anomalies are displayed in two colour density intervals only. In such a way fig. 5 highlights anomaly intensity, whereas fig. 6 highlights anomaly frequency (or wavelength). 


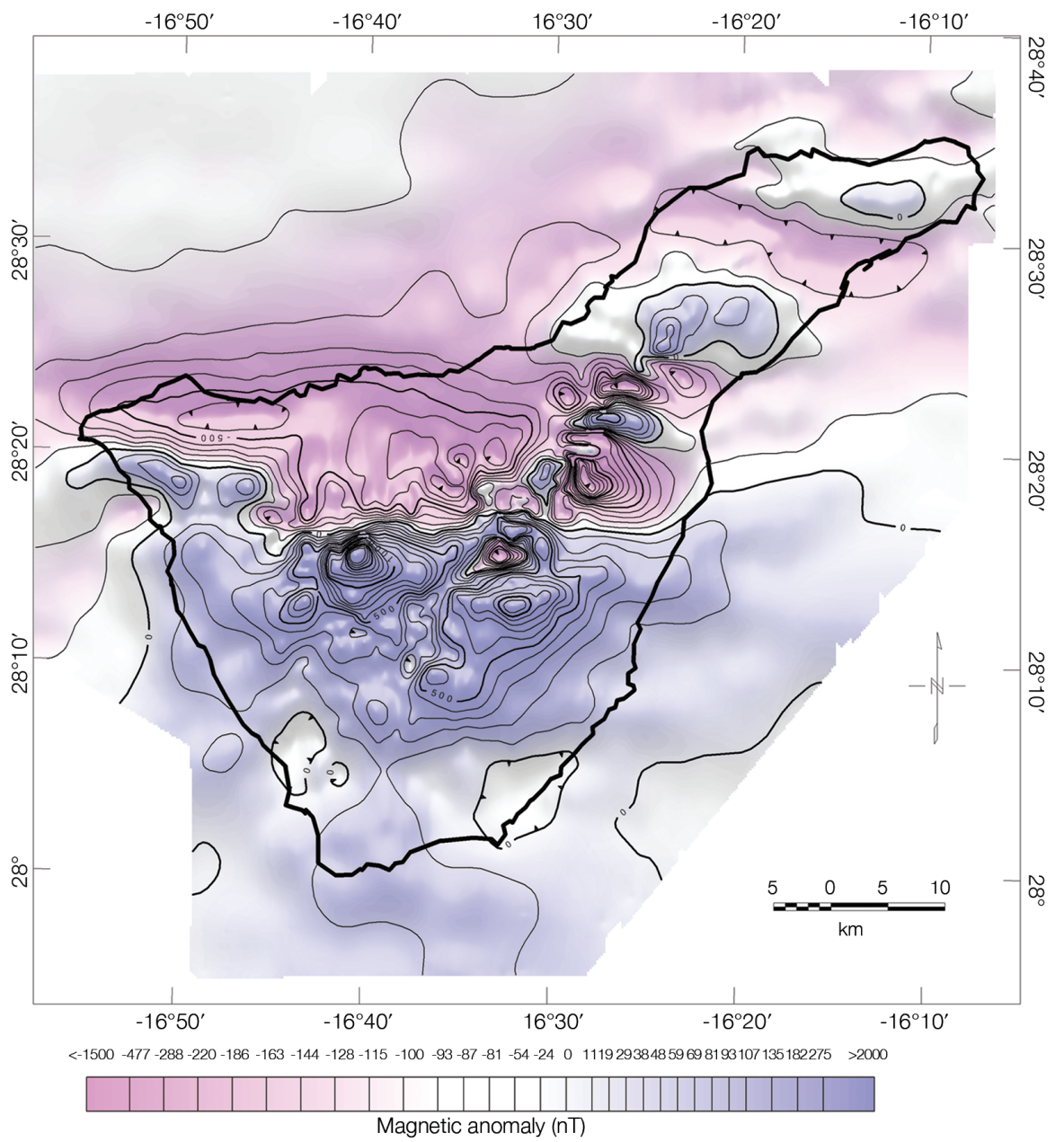

Fig. 6. Contoured magnetic anomaly map (total intensity) of Tenerife Island plotted in two colour density intervals to highlight anomaly frequency and wavelength. Latitude and longitude are north and west from Greenwich respectively.

\section{Discussion and conclusions}

The new high-resolution magnetic anomaly data over Tenerife Island and its surrounding marine areas confirm the regional magnetic anomaly pattern in the 1993 aeromagnetic survey (e.g., Blanco-Montenegro, 1997; Araña et al., 2000). However, the 2006 data set also images shallower and much higher frequency crustal magnetic sources for important new constraints on the complex volcanic history of Tenerife. The advantages of the new anomaly field (figs. 5 and 6) are particularly evident over Las Cañadas volcanic edifice where the most intense anomalies are resolved in unprecedented detail. These remarkable features include the higher frequency anomalies that extend from the eastern Las Cañadas caldera northeastwards as a ridge over the Dorsal de Pedro Gil (DPG in fig. 1).

Lower intensity and longer wavelength anomalies characterize the oldest shield volcanic edifices of Teno (TN), Anaga (A), and 
Roque del Conde (RC). These edifices also exhibit high magnetic gradients to constrain additional details of their complex volcanic development. Clearly, interpreting the new anomaly field constraints will be challenging because they include the superposed magnetic effects of many subaerial volcanic events from the past 12 Ma (Guillou et al., 2004). However, new advances in our understanding of the region's tectonics, geochronology, and paleomagnetism (e.g., Ancochea et al., 1999; Marinoni and Gudmundsson, 2000; Thirwall et al., 2000; Guillou et al., 2004; Soriano et al., 2006) provide a solid basis for exploiting the higher resolution aeromagnetic data for improved insights on Tenerife's crustal properties, processes, and evolution.

\section{Acknowledgements}

This work was funded by the Spanish Ministry of Education and Science through the projects: CGL2004-21643-E (TEGETEIDE coordinated by A. Garcia); CGL2004-05744-C04 (TEIDEVS) and CGL2005-25066-E (METO-TEIDE). We greatly appreciate the support and collaboration of the Instituto Geografico Nacional during the aeromagnetic survey. We also thank C. Cifuentes and J. Ríos (Helicópteros Insulares, S.L.) for their enthusiastic and competent contributions to the aeromagnetic campaign. The participation of I. Blanco-Montenegro in this work was supported by the Spanish Ministry of Education and Science (Secretaría de Estado de Universidades e Investigación, Ayudas de Movilidad PR-20060308 y PR-2007-0049). COTEC España and COTEC Italia promoted the cooperation very actively.

\section{REFERENCES}

Ancochea, E., M.J. Huertas, J.M. Cantagrel, J. Coello, J. M. Fúster, N. Arnaud and E. Ibarrola (1999): Evolution of the Cañadas edifice and its implications for the origin of the Cañadas caldera (Tenerife, Canary Islands), J. Volcanol. Geotherm. Res., 88, 177-199.

Araña, V., A.G. Camacho, A. García, F.G. Montesinos, F.G., I. Blanco, R. Vieira and A. Felpeto (2000): Internal structure of Tenerife (Canary Islands) based on gravity, aeromagnetic and volcanological data, J. Volcanol. Geotherm. Res., 103, 43-64.
BlanCo-Montenegro, I. (1997): Análisis e interpretación de las anomalías magnéticas de tres calderas volcánicas: Decepción (Shetland del Sur, Antártica), Furnas (S. Miguel, Azores) y Las Cañadas del Teide (Tenerife, Canarias), Ph.D. Thesis (Universidad Complutense de Madrid).

Blanco-Montenegro, I., R. De Ritis and M. Chiappini (2007): Imaging and modelling the subsurface structure of volcanic calderas with high-resolution aeromagnetic data at Vulcano (Aeolian Islands, Italy), Bull. Volcanol., 69 (6), 643-659, doi: 10.1007/s00445-006-0100-7.

CARRACEDO, J.C. (1994): The Canary Islands: an example of structural control on the growth of large oceanic-island volcanoes, J. Volcanol. Geotherm. Res., 60, 225-241.

Chiappini, M., F. Ferraccioli, V. Bosi, E. Bozzo, G. CaneVA and R. Funiciello (1998): An Experimental aeromagnetic survey in the Volturno Valley area (southeastern Latium), Ann. Geofis., 41 (3), 469-476.

Chiappini, M., A. Meloni, E.Boschi, O. Faggioni, N. BeVERINI, C. CARMISCIANO and I. MARSON (2000): On shore-off shore integrated shaded relief magnetic anomaly map at sea level of Italy and surrounding areas, Ann. Geofis., 43 (5), 983-989.

Chiappini, M., F. Ferraccioli, E. Bozzo and D. Damaske (2002): Regional compilation and analysis of aeromagnetic anomalies for the Transantarctic Mountains-Ross Sea sector of the Antarctic, Tectonophysics, 347, 121137.

De Ritis, R., I. Blanco-Montenegro, G. Ventura and M. CHIAPPINI (2005): Aeromagnetic data provide new insights on the tectonics and volcanism of Vulcano Island and offshore areas (Southern Tyrrhenian Sea, Italy), Geophys. Res. Lett., 32 (L15305), doi: 10.1029/ 2005 GL023465.

De Ritis, R., G. Ventura and M. Chiappini (2007): Aeromagnetic anomalies reveal hidden tectonic and volcanic structures in the central sector of the Aeolian Islands, Southern Tyrrhenian Sea, Italy, J. Geophys. Res., 112 (B10105), doi: 10.1029/2006JB004639.

García, A., I. Blanco, J.M. TorTA and I. Socías (1997): High-resolution aeromagnetic survey of the Teide volcano: a preliminary analysis, Ann. Geofis., XL (2), 329340.

García, A., J. Vila, R. Ortiz, R. Maciá, R. Sleeman, J.M. Marrero, N. SANChEZ, M. TÁrraga and A.M. CorREIG (2006): Monitoring the reawakening of Canary Islands' Teide volcano, Eos, 87 (6), 61,65.

Gottsmann, J., L. Wooler, J. Martí, J. Fernández, A.G. CAmacho, P.J. GonzÁlez, A. García and H. Rymer (2006): New evidence for the reawakening of Teide volcano, Geophys. Res. Lett., 33 (L20311), doi: 10.1029/ 2006 GL027523.

Guillou, H., J.C. Carracedo, R. Paris and F. Pérez-TorRADO (2004): Implications for the early shield-stage evolution of Tenerife from $\mathrm{K} / \mathrm{Ar}$ ages and magnetic stratigraphy, Earth Planet. Sci. Lett., 222, 599-614.

Lénat, J.-F., B. Gibert-Malengreau and A. Galdeano (2001): A new structural model for the evolution of the volcanic island of Réunion (Indian Ocean), J. Geophys. Res., 106 (B5), 8645-8663.

MacMillan, S. and S. Maus (2005): International geomagnetic reference field - The tenth generation, Earth Planets Space, 57 (12), 1135-1140. 
Marinoni, L.B. and A. Gudmundsson (2000): Dykes, faults and paleostresses in the Teno and Anaga massifs of Tenerife (Canary Islands), J. Volcanol. Geotherm. Res., 103, 83-103.

Martí, J. and A. Gudmundsson (2000): The Las Cañadas caldera (Tenerife, Canary Islands): an overlapping collpase caldera generated by magma-chamber migration, J. Volcanol. Geotherm. Res., 103, 161-173.

SocíAs, I. and J. MÉzcuA (1996): Levantamiento aeromagnético del archipiélago canario, Publ. Técnica no. 35 (Instituto Geográfico Nacional, Madrid, Spain), pp. 28.

Soriano, C., I. Galindo, J. Martí and J. WolfF (2006):

Conduit-vent structures and related proximal deposits in the Las Cañadas caldera, Tenerife, Canary Islands, Bull. Volcanol., 69, 217-231.

Thirlwall, M.F., B.S. Singer and G.F. MArriner (2000): $39 \mathrm{Ar}-40 \mathrm{Ar}$ ages and geochemistry of the basaltic shield stage of Tenerife, Canary Islands, Spain, J. Volcanol. Geotherm. Res., 103, 247-297.

WATTS, A.B. and D.G. MAsson (1995): A giant landslide on the north flank of Tenerife, Canary Islands, J. Geophys. Res., 100, 24487-24498.

(received September 1, 2007; accepted October 29, 2007) 